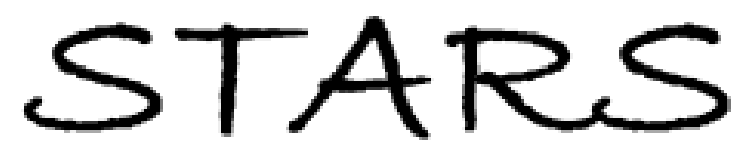

University of Central Florida

STARS

$1-1-2007$

\title{
Formation, thermal stability, and surface composition of size- selected AuFe nanoparticles
}

\author{
A. Naitabdi \\ University of Central Florida \\ Roldan Cuenya \\ University of Central Florida
}

Find similar works at: https://stars.library.ucf.edu/facultybib2000 University of Central Florida Libraries http://library.ucf.edu

This Article is brought to you for free and open access by the Faculty Bibliography at STARS. It has been accepted for inclusion in Faculty Bibliography 2000 s by an authorized administrator of STARS. For more information, please contact STARS@ucf.edu.

\section{Recommended Citation}

Naitabdi, A. and Cuenya, Roldan, "Formation, thermal stability, and surface composition of size-selected AuFe nanoparticles" (2007). Faculty Bibliography 2000s. 7462.

https://stars.library.ucf.edu/facultybib2000/7462

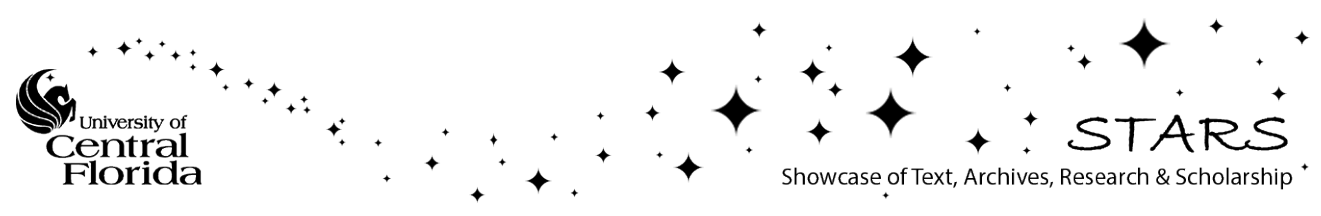




\section{Formation, thermal stability, and surface composition of size-selected AuFe nanoparticles}

Cite as: Appl. Phys. Lett. 91, 113110 (2007); https://doi.org/10.1063/1.2784957

Submitted: 18 July 2007 . Accepted: 23 August 2007. Published Online: 13 September 2007

A. Naitabdi, and B. Roldan Cuenya

\section{ARTICLES YOU MAY BE INTERESTED IN}

Synthesis of monosized magnetic-optical AuFe alloy nanoparticles

Journal of Applied Physics 103, $07 D 529$ (2008); https://doi.org/10.1063/1.2837619

Enhanced thermal stability and nanoparticle-mediated surface patterning: $\mathrm{Pt} / \mathrm{TiO}_{2}(110)$

Applied Physics Letters 94, 083102 (2009); https://doi.org/10.1063/1.3083557

Structure and phonon density of states of supported size-selected ${ }^{57} \mathrm{FeAu}$ nanoclusters: A nuclear resonant inelastic $x$-ray scattering study

Applied Physics Letters 95, 143103 (2009); https://doi.org/10.1063/1.3236539

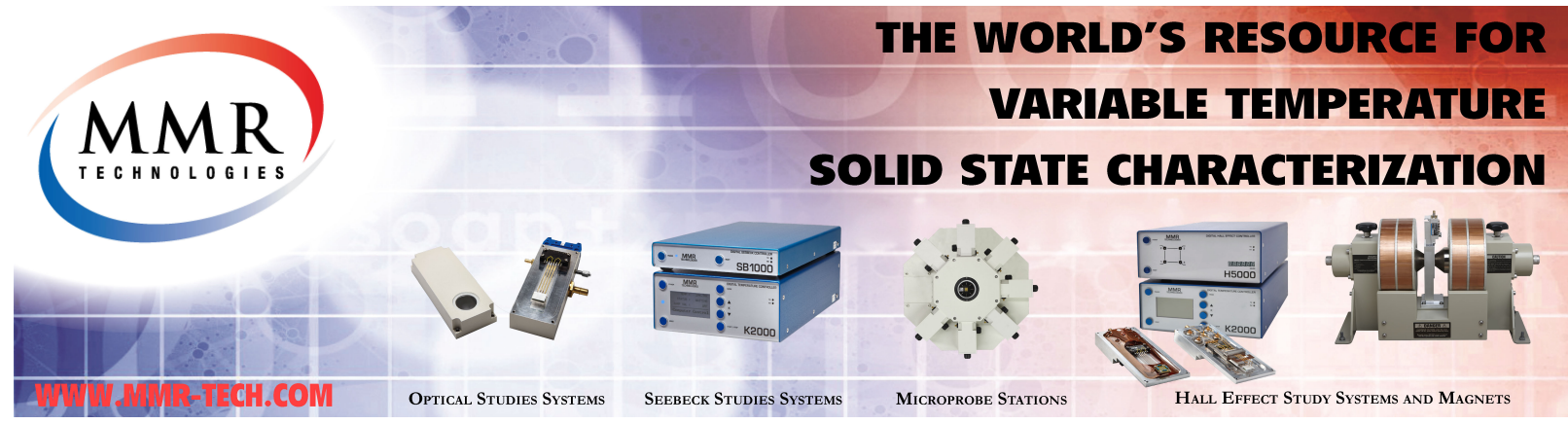




\title{
Formation, thermal stability, and surface composition of size-selected AuFe nanoparticles
}

\author{
A. Naitabdi and B. Roldan Cuenya ${ }^{a)}$ \\ Department of Physics, University of Central Florida, Orlando, Florida 32816, USA
}

(Received 18 July 2007; accepted 23 August 2007; published online 13 September 2007)

\begin{abstract}
The surface composition of isolated $\mathrm{Au}_{0.5} \mathrm{Fe}_{0.5}$ nanoparticles (NPs) synthesized by micelle encapsulation and supported on $\mathrm{TiO}_{2}(110)$ has been investigated. The study reveals that phase-segregated structures are present after annealing at $300{ }^{\circ} \mathrm{C}$. A subsequent thermal treatment at $700{ }^{\circ} \mathrm{C}$ resulted in the formation of a AuFe alloy. At this temperature, a state characteristic of $\mathrm{Fe}$ was identified at the NPs' surface. Annealing at $900{ }^{\circ} \mathrm{C}$ resulted in the disappearance of the $\mathrm{Fe}$ surface state, which is attributed to Au segregation to the surface. The initial hexagonal NP arrangement on the $\mathrm{TiO}_{2}(110)$ surface was preserved up to $900{ }^{\circ} \mathrm{C}$. At $1000{ }^{\circ} \mathrm{C}$, Au desorption was observed. () 2007 American Institute of Physics. [DOI: 10.1063/1.2784957]
\end{abstract}

The physical and chemical properties of bimetallic alloy nanostructures differ strongly from those of their monometallic counterparts. ${ }^{1-4}$ In the field of heterogeneous catalysis, oxide-supported bimetallic nanoparticles are known to exhibit remarkably high activities and enhanced selectivities. This is due to their ability to lower the energy barrier of a specific chemical reaction ${ }^{5}$ and their enhanced resistance against poisoning. ${ }^{6}$ AuFe clusters have been proven active for the structure-sensitive low-temperature $\mathrm{CO}$ oxidation $^{7}$ reaction. However, the structure and thermal stability of AuFe nanoparticles (NPs) are still not well understood.

In the present work, scanning tunneling microscopy and spectroscopy (STM and STS) were used to investigate the surface composition of self-assembled size-selected AuFe nanoparticles. Differential conductivity $(d I / d V)$ spectra were measured on the surface of isolated AuFe NPs after different annealing treatments to gain insight into their local density of states (LDOS). This local spectroscopic method has been used in the past to identify the chemical composition of surface alloys containing $\mathrm{Fe}: \mathrm{Fe} / \mathrm{Pt}(111),{ }^{8} \mathrm{Cr} / \mathrm{Fe}(001),{ }^{9}$ and $\mathrm{Au} / \mathrm{Fe}(001){ }^{10}$ The well-known $\mathrm{Fe}$ surface state near the Fermi level $\left(E_{F}\right)$ (Ref. 11) which appears as a sharp feature in the $d I / d V$ curves is used as a signature of the presence of $\mathrm{Fe}$ atoms at the NP surface.

Self-assembled size-selected $\mathrm{Au}_{0.5} \mathrm{Fe}_{0.5}$ NPs were synthesized by encapsulation in diblock-copolymer micelles formed by dissolving polystyrene-block-poly(2vinylpyridine) $[\mathrm{PS}(x)-\mathrm{P} 2 \mathrm{VP}(y)$, with molecular weights $x$ $=81000$ and $y=14200 \mathrm{~g} / \mathrm{mol}]$ in toluene. Subsequently, two metal salts, $\left(\mathrm{HAuCl}_{4} \cdot 3 \mathrm{H}_{2} \mathrm{O}\right)$ and $\left(\mathrm{FeCl}_{3}\right)$ were added simultaneously at equal concentration to the polymeric solution. The complete encapsulation of the $\mathrm{Au}$ and $\mathrm{Fe}$ compounds inside the micelles was achieved when a metal salt to PSP2VP concentration ratio of 0.6 was used. Following this synthesis method, for a given particle size [determined by the molecular weight of the polymer core (P2VP)], the alloy composition can be easily tuned by changing the relative concentration of the two metal salts. The interparticle distance is determined by the length of the polymer tail (PS). A monolayer-thick film of NPs was obtained by dip coating (ex situ) a $\mathrm{TiO}_{2}(110)$ single crystal into the gold-iron polymeric

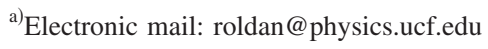

solution. This substrate was previously cleaned in ultrahigh vacuum (UHV) by $\mathrm{Ar}^{+}$sputtering $(1 \mathrm{keV})$ and annealing cycles at $950{ }^{\circ} \mathrm{C}$ to obtain optimum conductive properties. ${ }^{12}$ The sample was then introduced into a UHV system (SPECS, GmbH) for in situ chemical and electronic characterizations. The encapsulating polymer was removed in situ by $\mathrm{O}_{2}$-plasma exposure $\left(4.5 \times 10^{-5} \mathrm{mbar}, 80 \mathrm{~min}\right)$. Complete removal of the organic ligands was evidenced by the lack of C $1 s$ signal in X-ray photoelectron spectroscopy (XPS) measurements. Subsequently, the sample was annealed in situ for 20 min at $100{ }^{\circ} \mathrm{C}$ intervals from 300 to $800{ }^{\circ} \mathrm{C}$ and at 900 and $1000{ }^{\circ} \mathrm{C}$ for $10 \mathrm{~min}$. XPS and STM data were acquired after each thermal treatment. In order to minimize scanning artifacts due to tip contamination, our chemically etched $\mathrm{W}$ tip was cleaned by $\mathrm{Ar}^{+}$sputtering $(4 \mathrm{keV}, 4.3 \mu \mathrm{A})$ prior to each STS session.

Figure 1 shows STM images acquired at $15{ }^{\circ} \mathrm{C}$ on $\mathrm{AuFe}$
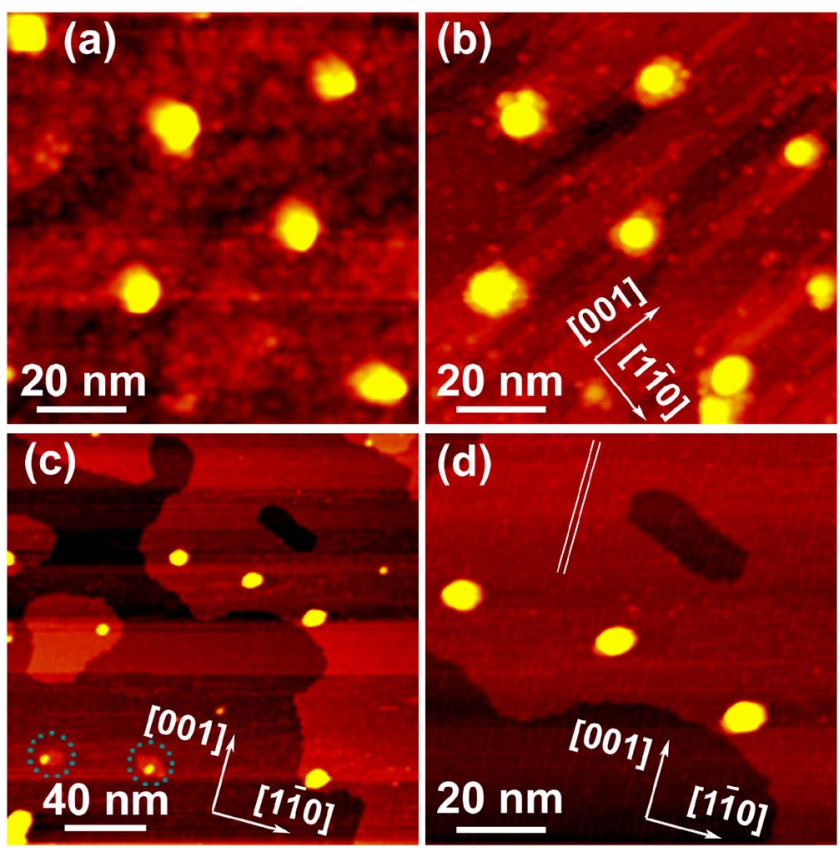

FIG. 1. (Color online) STM images $\left(V_{t}=1.0 \mathrm{~V}, I_{t}=0.30 \mathrm{nA}\right)$ of $\mathrm{Au}_{0.5} \mathrm{Fe}_{0.5}$ NPs on $\mathrm{TiO}_{2}(110)$ measured at $15^{\circ} \mathrm{C}$ after an $\mathrm{O}_{2}$-plasma treatment and subsequent annealing at $300{ }^{\circ} \mathrm{C}(20 \mathrm{~min})(\mathrm{a}), 900{ }^{\circ} \mathrm{C}(10 \mathrm{~min})(\mathrm{b})$, and $1000{ }^{\circ} \mathrm{C}(10 \mathrm{~min})[(\mathrm{c})$ and $(\mathrm{d})]$. 


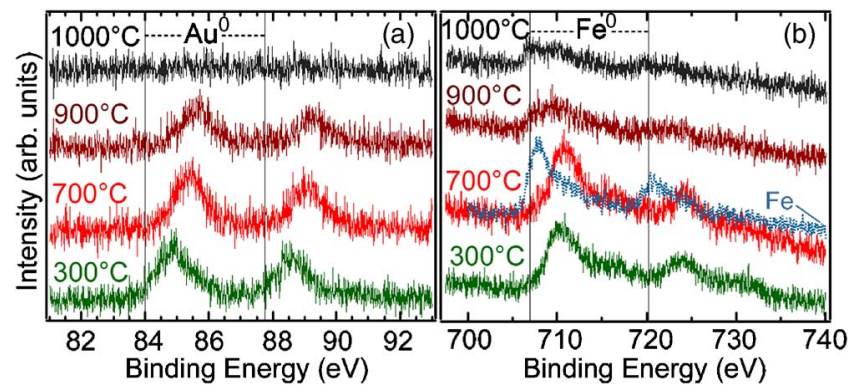

FIG. 2. (Color online) XPS spectra (Al $K \alpha, 1486.6 \mathrm{eV}$ ) of the $\mathrm{Au} 4 f$ (a) and Fe $2 p$ (b) core levels of AuFe NPs supported on $\mathrm{TiO}_{2}(110)$ measured after an $\mathrm{O}_{2}$-plasma treatment and subsequent annealing in UHV from 300 to $1000{ }^{\circ} \mathrm{C}$. Reference lines corresponding to bulk Au $4 f$ and Fe $2 p$ levels are also plotted. In (b), the spectrum labeled as $\mathrm{Fe}$ corresponds to monometallic Fe NPs deposited on $\mathrm{TiO}_{2}$.

NPs on $\mathrm{TiO}_{2}(110)$ after $\mathrm{O}_{2}$-plasma treatment and subsequent annealing at $300{ }^{\circ} \mathrm{C}(\mathrm{a}), 900{ }^{\circ} \mathrm{C}(\mathrm{b})$, and $1000{ }^{\circ} \mathrm{C}$ [(c) and (d)]. Size-selected AuFe NPs with well-defined interparticle distances $(l)$ can be observed. STM images from similarly synthesized $\mathrm{Au}$ NPs showing hexagonal NP arrangement over larger substrate areas can be found in Ref. 13. In the temperature range from 300 to $900{ }^{\circ} \mathrm{C}$, a stable $l$ of $\sim 49 \mathrm{~nm}$ was measured. However, a significant change in the morphology of the $\mathrm{TiO}_{2}(110)$ surface (i.e., a decrease in the roughness caused by the $\mathrm{O}_{2}$ plasma) was observed after annealing at $900{ }^{\circ} \mathrm{C}$ [Fig. 1(b)]. At this temperature, the onset of the $\mathrm{TiO}_{2}(110)-(1 \times 1)$ surface reconstruction appears. In addition, at least three $\mathrm{TiO}_{2}$ atomic layers are removed in the vicinity of the AuFe NPs upon annealing at $900{ }^{\circ} \mathrm{C}$. By contrast, the presence of the AuFe NPs seems to stabilize $\mathrm{TiO}_{2}$ layers underneath and on the perimeter of the NPs. No diffusion of AuFe NPs or coarsening was observed at least up to $900{ }^{\circ} \mathrm{C}$. This remarkable stability reflects the strong interaction between the AuFe NPs and the underlying $\mathrm{TiO}_{2}$ support. Only a small decrease in the size of NPs was observed after annealing from $300{ }^{\circ} \mathrm{C}$ (height $h=4.6 \pm 0.4 \mathrm{~nm}$ ) to $800{ }^{\circ} \mathrm{C}$ $(4.3 \pm 0.3 \mathrm{~nm})$. However, the annealing at $900{ }^{\circ} \mathrm{C}$ significantly reduced the average NP size to $h=3.2 \pm 0.3 \mathrm{~nm}$. This height change is likely to result from (i) atomic desorption from the cluster surface above $800{ }^{\circ} \mathrm{C}$ and (ii) a change in the NP shape (flatter NPs). After annealing at $1000{ }^{\circ} \mathrm{C}$, the hexagonal NP arrangement is lost [Fig. 1(c)], bimodal size distribution $\left(h_{1}=2.5 \pm 0.5 \mathrm{~nm}, h_{2}=1.0 \pm 0.6 \mathrm{~nm}\right)$ is observed. Further, large terraces of the $\mathrm{TiO}_{2}(110)-(1 \times 1)$ reconstruction with atomic rows along the [001] direction appear ${ }^{12}$ [Fig. 1(d)].

XPS data obtained after $\mathrm{O}_{2}$ plasma and annealing at $300{ }^{\circ} \mathrm{C}$ indicate the presence of $\mathrm{Fe}^{3+}\left(710.5 \mathrm{eV}, 2 p_{3 / 2}\right)$ in the $\mathrm{AuFe}$ NPs (Fig. 2). The large binding energy (BE) measured for $\mathrm{Au}(0.8 \mathrm{eV}$ larger than bulk $\mathrm{Au}, 84.0 \mathrm{eV})$ is attributed to the interaction with the nearby $\mathrm{Fe}_{2} \mathrm{O}_{3}$ environment. At $700{ }^{\circ} \mathrm{C}$, a further increase in the $\mathrm{BE}$ of $\mathrm{Au}$ is observed, indicating the formation of the AuFe alloy $\left(85.4 \mathrm{eV}, 4 f_{7 / 2}\right)$. However, no significant shift in the Fe $2 p$ core level is observed, suggesting that the $\mathrm{BE}$ of $\mathrm{Fe}$ in a AuFe alloy $(710.9 \mathrm{eV})$ is similar to that of $\mathrm{Fe}_{2} \mathrm{O}_{3}$. To corroborate this point, the BE of similarly synthesized monometallic Fe clusters was measured after annealing at $700{ }^{\circ} \mathrm{C}$ [curve "Fe" in Fig. 2(b)]. In this case, a much lower BE value was obtained $\left(707.7 \mathrm{eV}, 2 p_{3 / 2}\right)$. At $900{ }^{\circ} \mathrm{C}$, a marked decrease in the $\mathrm{Fe}$ signal of the AuFe NPs is observed $(\sim 40 \%)$, while the Au

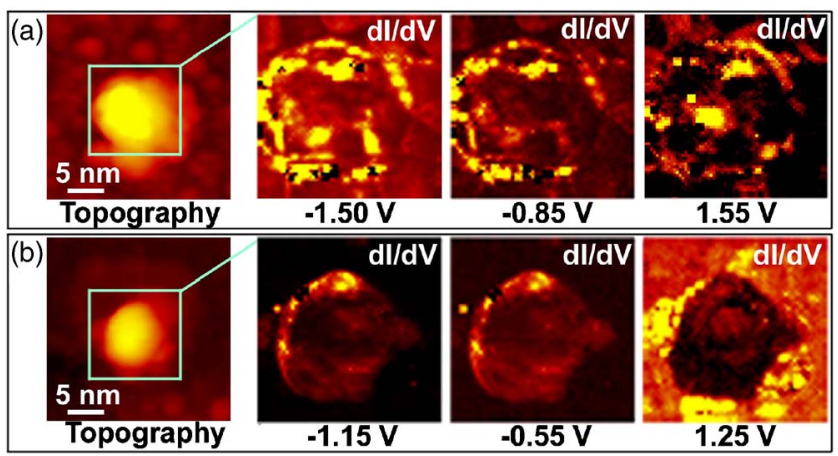

FIG. 3. (Color online) STM images (topography) and $d I / d V$ maps of two typical AuFe NPs supported on $\mathrm{TiO}_{2}(110)$ measured after $\mathrm{O}_{2}$-plasma treatment and annealing at $300{ }^{\circ} \mathrm{C}$ (a) and $900{ }^{\circ} \mathrm{C}(\mathrm{b})$. $d I / d V$ maps are recorded using a $(64 \times 64)$ grid over an area of $12.5 \times 12.5 \mathrm{~nm}^{2}$ (light blue squares).

signal is nearly constant $(\sim 3 \%$ decrease due to minimal $\mathrm{Au}$ desorption at this temperature). Since $\mathrm{Au}$ is expected to desorb at lower temperatures than $\mathrm{Fe}$, the stronger reduction in the XPS Fe signal is most likely due to Au segregation to the $\mathrm{NP}$ surface. The complete desorption of $\mathrm{Au}$ and the partial $\mathrm{Fe}$ reduction $\left(\mathrm{Fe}^{0}, 707 \mathrm{eV}\right)$ as well as desorption occur at $1000{ }^{\circ} \mathrm{C}$. The oxidized Fe species observed at $1000{ }^{\circ} \mathrm{C}$ are attributed to the $\mathrm{Fe} / \mathrm{TiO}_{2}$ interface.

Spatially resolved STS measurements have been performed using $I-V$ acquisition grids centered on individual $\mathrm{AuFe}$ NPs in order to get insight into the electronic local density of states, alloy composition, and segregation phenomena at the nanoscale.

Figure 3 shows $d I / d V$ maps recorded on two AuFe NPs after annealing at $300{ }^{\circ} \mathrm{C}$ [Fig. 3(a) ] and $900{ }^{\circ} \mathrm{C}$ [Fig. 3(b)]. An inhomogeneous $d I / d V$ distribution is observed after the low-temperature annealing. Further, the presence of individual grains within each AuFe NP is evident from Fig. 3(a) at $1.55 \mathrm{~V}$. Similar $d I / d V$ distributions were observed on several other NPs in our sample after annealing at $300{ }^{\circ} \mathrm{C}$, indicating the lack of alloying between $\mathrm{Au}$ and Fe. Annealing at $900{ }^{\circ} \mathrm{C}$ [Fig. 3(b)] results in a featureless $d I / d V$ distribution within individual AuFe NPs, indicating the coalescence of the Au and Fe grains. A more in-depth study of the electronic properties of these NPs can be made by analyzing normalized $d I / d V$ curves $[(d I / d V) /(I / V) \propto(\mathrm{LDOS})]$ obtained at specific NP locations.

Figure 4 shows normalized $d I / d V$ curves recorded on isolated AuFe NPs after annealing at $300{ }^{\circ} \mathrm{C}(\mathrm{a}), 700{ }^{\circ} \mathrm{C}(\mathrm{b})$, and $900{ }^{\circ} \mathrm{C}(\mathrm{c})$. Following Ref. 14, a moderate broadening factor, $\varepsilon^{2}=0.002(\mathrm{nA} / \mathrm{V})^{2}$, has been applied to the total conductivity $(\overline{I / V})=\sqrt{(I / V)^{2}+\varepsilon^{2}}$ to eliminate excessive noise in the bandgap region and the divergence of $(d I / d V) /(I / V)$ at the band edges. The curves labeled " $R-\mathrm{TiO}_{2}$ " were recorded on the $\mathrm{TiO}_{2}$ surface far away from AuFe NPs after each thermal treatment. In Fig. 4(a), the LDOS of the $\mathrm{TiO}_{2}$ substrate exhibits a net bandgap of $\sim 1 \mathrm{eV}$, with the edge of the conduction band minimum located $\sim 0.3 \mathrm{eV}$ above $E_{F}$. Within the bandgap region, the increase of the LDOS at $\sim$ -0.9 and $\sim-1.4 \mathrm{eV}$ is due to the presence of $\mathrm{O}$ vacancies on the reduced $\mathrm{TiO}_{2}$ surface $\left(R-\mathrm{TiO}_{2}\right)$ after annealing at $300{ }^{\circ} \mathrm{C}$. The creation of $\mathrm{O}$ vacancies results in free electron charge which is partially transferred to adjacent $\mathrm{Ti} 3 d$ levels. These levels are associated with $\mathrm{Ti}$ ions in the $3^{+}$oxidation state and appear as occupied states within the bandgap. ${ }^{15}$ In Fig. 3(b), the LDOS of $R-\mathrm{TiO}_{2}$ shows an enhancement of the 


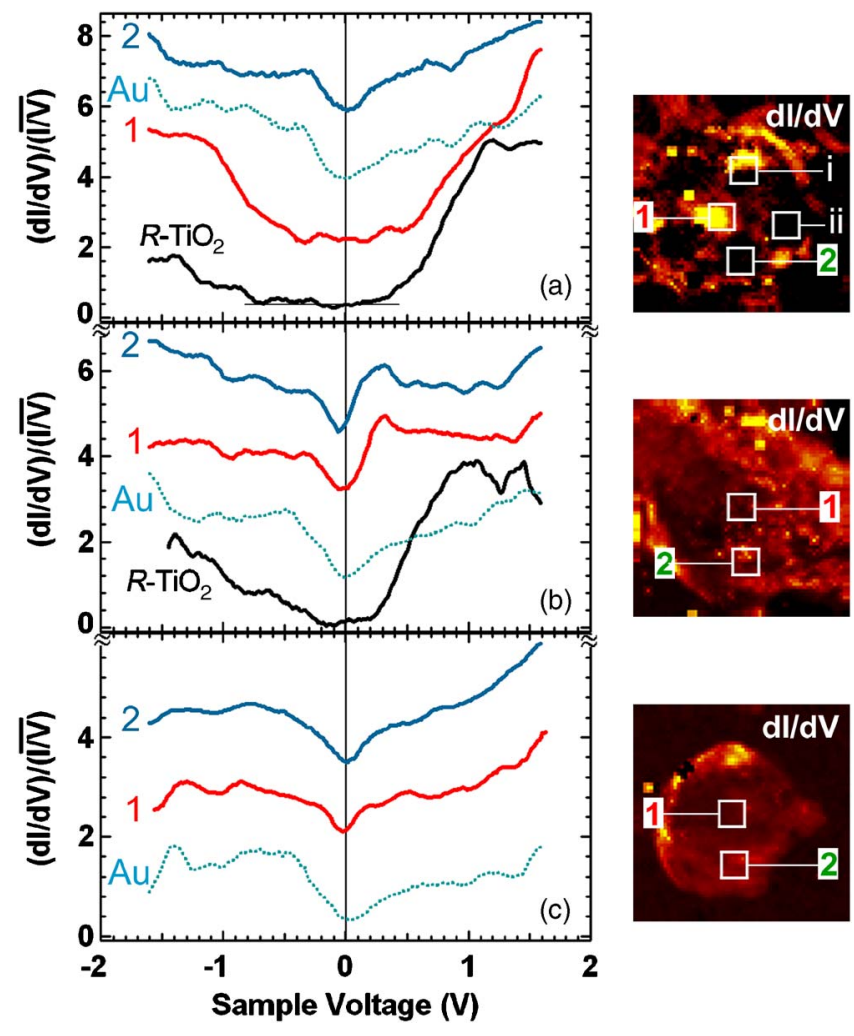

FIG. 4. (Color online) Normalized differential conductivity curves measured on three size-selected AuFe NPs deposited on $\mathrm{TiO}_{2}(110)$ after $\mathrm{O}_{2}$ plasma and subsequent annealing at $300{ }^{\circ} \mathrm{C}$ (a), $700{ }^{\circ} \mathrm{C}$ (b), and $900{ }^{\circ} \mathrm{C}(\mathrm{c})$. The insers are $d I / d V$ images indicating the position of the acquisition grids used. Each curve was obtained from the average of 64 individual $I-V$ curves taken over different $1.5 \times 1.5 \mathrm{~nm}^{2}$ regions inside each NP. Dotted curves were obtained on a reference sample containing pure Au NPs of similar size deposited on $\mathrm{TiO}_{2}(110)$ and annealed in UHV at identical temperatures.

conductivity in the bandgap (at -0.6 and $-1.1 \mathrm{eV}$ ) resulting from the increase of $\mathrm{Ti} 3 d$ states as additional $\mathrm{O}$ vacancies are created after annealing at $700{ }^{\circ} \mathrm{C}$. A similar effect is observed after annealing at $900{ }^{\circ} \mathrm{C}$ (not shown).

Curve 1 in Fig. 4(a) was acquired at the top of a AuFe $\mathrm{NP}$ after annealing at $300{ }^{\circ} \mathrm{C}$. The large bandgap $(\sim 0.75 \mathrm{eV})$ measured at this NP location can be attributed to oxidized $\mathrm{Fe}$ atoms in $\mathrm{Fe}_{2} \mathrm{O}_{3}$, since no metal-to-nonmetal transition related to quantum size effects is expected for a NP of this size $(h=4.6 \mathrm{~nm})$. Our XPS measurements corroborate the presence of iron atoms in the $\mathrm{Fe}^{3+}$ state at this temperature [Fig. 2(b)] due to the $\mathrm{O}_{2}$-plasma treatment used to remove the encapsulating polymeric shell. Curve 2 in Fig. 4(a), recorded in the perimeter area of this AuFe NP, does not show such a large bandgap and we identify this location as a gold-rich region. The $\mathrm{Au}_{2} \mathrm{O}_{3}$ formed upon NP exposure to $\mathrm{O}_{2}$ plasma is easily decomposed well below $300{ }^{\circ} \mathrm{C}$. A similar curve was measured on a pure Au NP (curve "Au") from a reference sample with $\mathrm{Au}$ NPs on $\mathrm{TiO}_{2}(110)$ annealed at $300{ }^{\circ} \mathrm{C}$. Curves comparable to 1 and 2 (not shown) were measured on regions (i) and (ii), respectively, in Fig. 4(a). From our STS analysis, we infer that Au and Fe at this temperature are phase separated.

After annealing at $700{ }^{\circ} \mathrm{C}$ [Fig. 4(b)], curves 1 and 2 show a peak in the LDOS $\sim 0.25 \mathrm{eV}$ above $E_{F}$ which is attributed to Fe surface states. These states are not observed in the LDOS obtained on a pure Au NP after an identical thermal treatment (curve $\mathrm{Au}$ ). Band structure calculations ${ }^{11}$ of the bulk $\mathrm{Fe}(001)$ surface show the presence of states with high localization and surface amplitudes along the $\bar{\Gamma}-\bar{X}$ direction of the Brillouin zone. However, mainly states at the center of the Brillouin zone $(\bar{\Gamma})$ above $E_{F}$ are accessible to STS, and they arise from nearly unperturbed $d_{3 z^{2}-r^{2}}$ orbitals. ${ }^{11}$

The observation of the $\bar{\Gamma}$ surface state at different locations within the AuFe NPs' surface indicates the formation of a $\mathrm{Au}-\mathrm{Fe}$ alloy at $700{ }^{\circ} \mathrm{C}$. Bischoff et al. ${ }^{10}$ also reported the formation of an alloyed surface layer for the $\mathrm{Au} / \mathrm{Fe}(001)$ system after annealing at $700{ }^{\circ} \mathrm{C}$.

The composition of the NPs' surface was found to change after annealing at $900{ }^{\circ} \mathrm{C}$, namely, the spectroscopic feature from $\mathrm{Fe}$ states vanishes from the LDOS [Fig. 4(c)] (curves 1 and 2). This indicates a decrease in the number of $\mathrm{Fe}$ atoms at the NP surface, leading to a Au-rich surface due to the segregation of Au atoms toward the NP surface. This is consistent with our XPS data at $900{ }^{\circ} \mathrm{C}$ [Fig. 2(b)]. The favorable segregation of $\mathrm{Au}$ atoms to the NP surface may result from the lower surface energy $\gamma$ of $\mathrm{Au}\left(\gamma_{\mathrm{Au}}=1.55 \mathrm{~J} / \mathrm{m}^{2}\right)$ as compared to $\mathrm{Fe}\left(\gamma_{\mathrm{Fe}}=3.47 \mathrm{~J} / \mathrm{m}^{2}\right),{ }^{16}$ as well as from the larger atomic volume of $\mathrm{Au}\left(\sim 12.5 \AA^{3}\right)$ with respect to $\mathrm{Fe}$ $\left(\sim 8.0 \AA^{3}\right) .{ }^{17}$

In conclusion, high stability was observed for $\mathrm{Au}_{0.5} \mathrm{Fe}_{0.5}$ NPs supported on $\mathrm{TiO}_{2}(110)$ up to an annealing temperature of $900{ }^{\circ} \mathrm{C}$. The preservation of the initial hexagonal NP arrangement indicates strong cluster-support interactions. STS measurements revealed that separated $\mathrm{Au}$ and Fe grains coexist within an individual AuFe NP after annealing at $300{ }^{\circ} \mathrm{C}$. A homogenous alloy is formed upon annealing at $700{ }^{\circ} \mathrm{C}$, with the marked appearance of an iron $d_{3 z^{2}-r^{2}}$ surface state. Further annealing at $900{ }^{\circ} \mathrm{C}$ was found to induce the formation of a Au-rich NP surface due to gold segregation.

This work was supported by NSF (CAREER, No. 0448491) and ACS-PRF (42701-G5) awards.

${ }^{1}$ C. T. Campbell, Annu. Rev. Phys. Chem. 41, 775 (1990).

${ }^{2}$ J. A. Rodriguez, Surf. Sci. Rep. 24, 225 (1996).

${ }^{3}$ G. F. Wang, M. A. Van Hove, P. N. Ross, and M. I. Baskes, Prog. Surf. Sci. 79, 28 (2005).

${ }^{4}$ A. Kolmakov and D. W. Goodman, Rev. Sci. Instrum. 74, 2444 (2003).

${ }^{5}$ A. F. Carlsson, M. Naschitzki, M. Baumer, and H. J. Freund, J. Phys. Chem. B 107, 778 (2003)

${ }^{6}$ A. M. Molenbroek, J. K. Norskov, and B. S. Clausen, J. Phys. Chem. B 105, 5450 (2001).

${ }^{7}$ R. M. Finch, N. A. Hodge, G. J. Hutchings, A. Meagher, Q. A. Pankhurst, M. R. H. Siddiqui, F. E. Wagner, and R. Whyman, Phys. Chem. Chem. Phys. 1, 485 (1999).

${ }^{8}$ M. F. Crommie, C. P. Lutz, and D. M. Eigler, Phys. Rev. B 48, 2851 (1993).

${ }^{9}$ A. Davies, J. A. Stroscio, D. T. Pierce, and R. J. Celotta, Phys. Rev. Lett. 76, 4175 (1996).

${ }^{10}$ M. M. J. Bischoff, T. K. Yamada, and H. van Kempen, Phys. Rev. B 67, 165403 (2003)

${ }^{11}$ J. A. Stroscio, D. T. Pierce, A. Davies, R. J. Celotta, and M. Weinert, Phys. Rev. Lett. 75, 2960 (1995).

${ }^{12}$ U. Diebold, J. Lehman, T. Mahmoud, M. Kuhn, G. Leonardelli, W. Hebenstreit, M. Schmid, and P. Varga, Surf. Sci. 411, 137 (1998).

${ }^{13}$ A. Naitabdi, L. K. Ono, and B. Roldan-Cuenya, Appl. Phys. Lett. 89, 043101 (2006).

${ }^{14}$ M. Prietsch, A. Samsavar, and R. Ludeke, Phys. Rev. B 43, 11850 (1991).

${ }^{15}$ Z. Klusek, A. Bustakiewicz, and P. K. Datta, Surf. Sci. 600, 1619 (2006).

${ }^{16}$ O. S. Hernan, A. L. V. de Parga, J. M. Gallego, and R. Miranda, Surf. Sci. 415, 106 (1998).

${ }^{17}$ J. Tersoff, Phys. Rev. Lett. 74, 434 (1995). 